\section{Early Clinical Manifestations of Infectious Mononucleosis}

SIR.-Dr. M. S. Pereira and her colleagues have published the results (Table VI) of investigations done on one of my patients (29 November, p. 526).

Unfortunately, because this patient also participated in a vaccine trial at the same time as he fell ill with infectious mononucleosis, Dr. Pereira and her colleagues were unable to include full clinical details in their paper. It seems possible that quite accidentally I happened to see the very earliest manifestations of infectious mononucleosis in this patient, and consider the history and course of the illness worth recording.

During the autumn of 1968 a 23-year-old medical student took part in a comparative trial of three vaccines against influenza A2 HongKong. Serum was obtained before and three weeks after administration of the vaccine. On 16 December he reported, as he had been requested, some very trivial symptoms. For two days he had felt unwell with slight occipital headache and slight general malaise, had slept badly, and had "a funny feeling in the throat". On examination the only abnormality found was minimal cervical adenopathy; the spleen was not felt. A throat swab yielded no bacterial pathogens, and routine viral investigations on throat and nose swabs, and paired sera, gave negative results. However, a blood film showed a few atypical mononuclear cells not uncommon in acute viral illness. A Monospot test was negative. Blood was taken on 16 December, and there was no fluorescent antibody present to $\mathrm{EB}$ virus on that occasion. By 22 December the patient had recovered, all symptoms had gone, and only minimal adenopathy remained. On 25 December he woke feeling "muzzy-headed", and by the evening he had a temperature of $103^{\circ} \mathrm{F}$. $\left(40^{\circ} \mathrm{C}\right)$. The next day he had fever, general aches and pains, a dry cough, and a sore throat. On examination on 27 December, he presented the typical clinical picture of infectious mononucleosis. He was a sick young man with a fever of $102^{\circ} \mathrm{F}$ and a pulse of $100 /$ minute, generalized adenopathy, and splenic enlargement to 2 $\mathrm{cm}$. below the costal margin. The fauces were red and inflamed, and there were shallow lesions on the fauces, buccal inucosae, and inside the lips. Monospot test was still negative, but became positive by 31 December. The blood film showed no abnormal mononuclear cells, but several were present a day later. A swinging temperature rising to $104^{\circ} \mathrm{F}$. persisted until 31 January when the Monospot and Paul-Bunnell tests became positive and he was put on prednisolone $(60 \mathrm{mg}$. initially, in rapidly decreasing doses) and responded with complete symptomatic recovery within 24 hours, and a drop of the temperature to normal within 12 hours. The throat also improved very rapidly. Fluorescent antibody to EB virus first appeared on 16 January (an earlier specimen was broken in the post), the titre rose, and has persisted at $1 / 80$ since. The subsequent course was uneventful.

The interest of this case lies in the apparently trivial onset of the illness, which

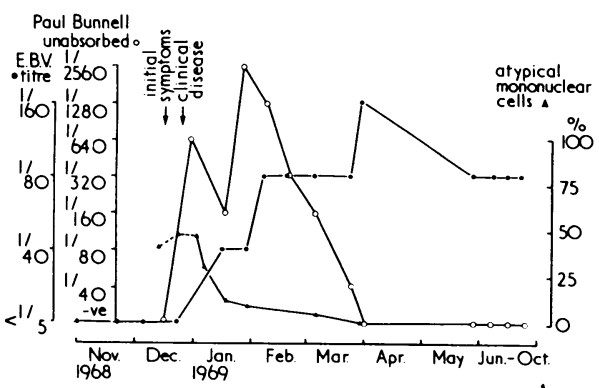

Clinical and laboratory events in infectiou mononucleosis in a male medical student aged 23 . would certainly have been missed but for an unrelated coincidence, and the time interval of about ten days before the classical symptoms and signs of infectious mononucleosis set in. One cannot help but speculate that what the clinician sees is some form of cellular immunological response to an acute infection which happened some ten days before. ${ }^{1}$ The success of steroid therapy, well recognized by clinicians who see many patients with glandular fever, ${ }^{2}$ is more readily understandable than it would otherwise have been, had steroids been given in the acute phase of the illness. I have since seen two further patients, both young males, with an identical history with the same complaint of mild malaise and "a funny feeling in the throat" preceding the classical clinical manifestations of infectious mononucleosis by about ten days.

I am grateful to Dr. MacCallum and Dr. Pereira for their virological investigations and to Dr. Pauline Emerson for frequent haematological investigations in this case.-I am, etc.,

Radcliffe Infirmary,

$$
\text { B. E. JUEL-JENSEN. }
$$

Oxford.

REFERENCES

Dameshek, W. in Infectious Mononucleosis, ed. R. L. Carter and H. G. Penman, p. 299. Blackwell, Prout, C. and Dalrymple, W. Fournal of the American College Health Association, 1966, 15 62.

\section{Corticosteroid Injections for Hay-fever}

SIR,-Despite clinical improvement in approximately $70 \%$ of patients treated with Depo-Medrone, Dr. M. A. Ganderton and others (8 February 1969 , p. 357) question the use of this preparation in the treatment of summer hay-fever. The clinical response to Depo-Medrone compared well with the other forms of treatment investigated and the authors noted that "there were no obvious side-effects" in the corticosteroid group. Furthermore, only $3 \%$ of the patients showed any reaction to Depo-Medrone whereas $25 \%$ and $35 \%$ respectively of the comparative groups (co-seasonal and pre-seasonal Allpy ral) showed post-injection reactions. Thu from the clinical standpoint methylprednisolone acetate was shown to be an excellen treatment for hay-fever (although in my experience only a small minority of patients require two injections) and the incidence of clinically significant side effects was confirmed as being virtually nil.

Despite these findings however, the authors express doubts whether the treatment "is justifiable." The sole reason for their doubt appears to be based on biochemical observations of the hypothalamic pituitary feed-back mechanism. Interpretation of the biochemical tests used to assess adrenal function is subject on which there is far from general agreement. Indeed, in a recent Lumleian lecture Cope" has pointed out that "we are no longer justified in making predictions about the stress response from observations of the feed-back mechanism" and has suggested that "we must therefore turn to the evidence of clinical observation itself." He also noted that one area where there does seem to be general agreement is that "after short courses of steroids the pituitary adrenal axis is little disturbed." Rejection of an efficacious treat- ment on the basis of adrenal function studies alone is therefore surely open to question, especially where in practice the treatment has proved to be remarkably safe.

I have found Depo-Medrone to be the best treatment by far for patients with hay-fever, and continue to achieve about an $80 \%$ success rate with a complete absence of any noteworthy side-effects. This experience regarding lack of observable side-effects following a short course of one or at most two injections is fairly general after years of widespread use of the preparation both intra-articularly and intra-muscularly in many thousands of patients. $^{2}$

In the continuing absence of any clinical evidence that a short course of Depo-Medrone has led to failure of an adrenal to respond to stress, the risk must by now surely be regarded as mainly theoretical. I therefore suggest that a single $2 \mathrm{ml}$. dose of DepoMedrone has claim to be considered the treatment of choice in the management of hayfever. The injection may be repeated after an interval of two or three weeks, although in my experience this is necessary in only a small minority of patients.-I am, etc.,

$$
\begin{aligned}
& \text { Blechingley, } \\
& \text { Surrey. }
\end{aligned}
$$

Basil Marshall.

\section{REFERENCES} 1 Cope, C. L., British Medical fournal, 1966, 2, 847.
2 Marshall, B. Y., Practitioner, 1965, 194, 676.

\section{Synovectomy of the Knee in Rheumatoid Arthritis}

SIR,-With reference to your leading article on synovectomy of the knee in rheumatoid arthritis (27 December, p.757), a long-term survey of synovectomy of the knee in rheumatoid arthritics carried out in Bath on 153 patients operated on between two and twenty years from survey (of whom $60 \%$ had been operated on more than ten years prior to the survey) revealed $70 \%$ excellent or satisfactory results in patients of all grades of joint damage. Operative assessment of these cases showed that $94 \%$ had joint cartilage damage, of which $72 \%$ showed severe cartilage damage.

Similar assessment of the six to ten year follow-up showed a similar satisfactory result, and it would appear that some $70 \%$ of patients requiring a pain-relieving operation will do well with a simple subtotal synovectomy. The patients whose knees degenerate in the early post-operative period would appear to have a severe progressive type of rheumatoid arthritis and appeared to do badly in any form of surgery, and patients whose knees have been satisfactory for a period of three or more years remained satisfactory for a prolonged period.-I am, etc.,

Bath, Somerset.

Phillip Bliss.

\section{Priorities in Treatment}

SIR,-In the past there has usually been a relationship between the severity of an illness and the waiting time before admission to hospital. Diseases that threatened life took priority in this respect over less serious conditions.

Recently one of my patients has had to 